\title{
PSYCHOSOCIAL FACTORS INFLUENCING LEARNING DIFFICULTIES AMONG INDIVIDUALS WITH SPECIAL NEEDS
}

\author{
ROTIMI OGUNTAYO ${ }^{1}$, SAMSON F. AGBEROTIMI ${ }^{2}$, JOHNSON T. OYELEKE ${ }^{3}$, ABAYOMI \\ O. OLASENI ${ }^{4}$, ADAM A. AYINDE \\ 1, 3, 4, 5 Department of Psychology, University of Ilorin, Ilorin, Nigeria \\ ${ }^{2}$ Lifestyle Disease Research Entity, North West University, Mafikeng, South Africa
}

(C) 2020 Rotimi Oguntayo, Samson F. Agberotimi, Johnson T. Oyeleke, Abayomi O. Olaseni, Adam A. Ayinde

This is an open access article distributed under the Creative Commons Attribution-NonCommercial-NoDerivs license (http://creativecommons.org/licenses/by-nc-nd/3.0/)

DOI: $10.1515 /$ eras-2020-0004

\begin{abstract}
This study examined the influence of psychosocial factors on learning difficulties among adolescents with special needs. A cross-sectional survey design was utilized. One hundred and twenty adolescents comprising $56.7 \%$ males were purposively selected among students at a facility for special needs individuals in Ilorin, Nigeria. Data were collected with a structured questionnaire containing perceived stigma of intellectual disability scale, social support questionnaire and Colorado learning difficulties questionnaire. Only individuals who voluntarily consented to participate were included in the study. Data were subjected to statistical analysis utilizing the SPSS v20. There was no significant gender difference on learning difficulties among individuals with special needs $(t)(118)=.138$, $\mathrm{p}>.05)$. Individuals with high perceived stigma reported significant higher learning difficulties compared to their peers with low perceived stigma $(\mathrm{t}(118)=15.70 ; \mathrm{p}<.05)$. There was a significant influence of type of disability on learning difficulty $(\mathrm{F}(2,117)=9.152, \mathrm{p}<.01)$; individuals with intellectual impairment exhibited more learning difficulty compared with those with visual impairment (8.09) and those with hearing impairment (11.62). The study recommends that government should reinforce law that protect individuals living with disability and enhance their learning in schools. It is also important that sufficient support services are made available for these students to reinforce their motivation for school learning.
\end{abstract}

\section{Keywords}

disability, learning difficulty, psychosocial factors, social support, stigma

\section{Introduction}

Learning difficulty has gained global attention among researchers because of its adverse effects on the victims and their family members. Specifically, disability is perceived as a serious burden on members of the family in sub-Sahara Africa, worst still, culture and belief make people perceive that the situation is a curse or spiritual punishment ordained by the supreme being (Bunning, Gona, Newton, \& Hartley, 2017); some of such disabilities are the physically and intellectually challenged, visually impaired and hearing impairment.

Learning difficulty is a major problem among students in all parts of the world, especially those with special needs. A study conducted by Kingdon and Cassen (2010) showed that about 2,800,000 children have learning difficulty in US alone. The study further indicated that the prevalence of social problems experienced by student with learning difficulties in the United States ranged between 38\% and 75\%. Paget, Mallewa, Chinguo, Mahabere-Chrambo, and Gladstone (2016) affirmed a high prevalence of learning difficulty in India and reported 
that nearly $25 \%$ of individuals with learning difficulties that get to see psychologists for treatment are from the lower and middle socioeconomic strata of society. In the Sub-Saharan African region however, despite evidence of learning difficulties as reported by few isolated studies, large sample or nation-wide survey to show national prevalence of learning difficulties among students, including persons with special needs, is scanty.

According to the Learning Disabilities Association of Canada (n.d.), learning difficulty could be referred to as "a number of disorders which may affect the acquisition, organization, retention, understanding or use of verbal or nonverbal information". For example, Berninger and May (2001) identified three specific learning disabilities, such as: dysgraphia, which affects writing abilities; dyslexia, which affects a complex range of abilities related to reading and language; and oral and written language learning disability, which includes the same impairments as dyslexia plus problems with morphological and syntactic coding and comprehension. Dyscalculia is another identified learning disability that affects the application of mathematical operations, and visual and spatial organizations (Hutchinson, 2007). Learning disabilities affect the way a person learns new things, deals with information, and communicates with others (American Psychiatric Association, 2013; Shakespeare, 2014).

In the recent time, several psychosocial factors associated with learning difficulties have gained the attention of researchers in the global enquiry into the issue of learning difficulties, in particular among vulnerable individuals and those with special needs. Evidence has shown that stigma is one of the major psychosocial problems that individuals with learning difficulties usually experience. In this vein, Bunning (2017) asserted that individuals with learning difficulties are often stigmatized in schools, organisations and in general society. Link and Phelan (2001) describe five components of stigmatization: labeling, stereotyping, separation, status loss, and discrimination within the context of power differential. Labeling is the recognition of differences and the assignment of social salience to those differences. Stereotyping is the assignment of negative attributes to socially salient differences. Stereotypical differences are differences that matter and are also deemed by others to be undesirable. Separation occurs when the reactions of others to these differences lead to a pronounced sense of "otherness."

In 2016, the Division for Social Policy and Development (DSPD) noted that globally, world people with disabilities, most especially learning disabilities, face attitudinal barriers including prejudice, stereotypes, and low expectations. These negative attitudes and inaccurate beliefs about disability can result in stigma (DSPD, 2016). From a related perspective, stigma arises when elements of labelling, stereotyping (negative evaluation of a label), and prejudice (endorsement of the negative stereotypes) combine to lead to status loss and discrimination for the stigmatized individual or group, and occur in situations where they are disempowered (Mostert, 2016; Scior, 2016). Stigma elicits negative responses such as pity, anxiety, avoidance, hostility, and even hatred and disgust (Scior, 2016).

Organizations working with people with learning disabilities have found that stigma often lies at the root of the discrimination, exclusion and low status, experienced by people with learning disabilities and their families in all aspects of their lives in low and middle income countries (Bond Disability and Development Group (DDG), 2017; DSPD, 2016; Mostert, 2016). Combined with poverty and other barriers, stigma and discrimination put people with learning disabilities' rights at risk (Inguanzo, 2017). At the individual level, stigma and discrimination can result in internalized oppression and feelings of shame, as people with disabilities may have to face great challenges in overcoming the negative views of their community or societies to achieve self-acceptance and a sense of pride in their lives (DDG, 2017; DSPD, 2016). 
When individuals lose status or are discriminated against because of their negatively evaluated differences, they experience enacted stigma. Link and Phelan go on to argue that stigmatization can only be directly enacted upon individuals when there is a power differential between those with the trait and those without, when those who have the negatively evaluated difference have less power than those who do not (Link \& Phelan, 2001). Stigmatizations of individual with learning disabilities usually occur because of the expectation that people with disabilities are less able to contribute to the good of the family and the community, and the assumption that they are a burden (Aley, 2016; Mostert, 2016).

In West Africa for example, children with disabilities were not believed to be capable of living independent lives and were expected to require constant help from nondisabled people (Mostert, 2016). This kind of expectation from people led most people with disabilities to be discriminated and deprived of social supports from people in the society. Studies revealed that individual with special needs are not only seen as financial and resources burden internally, but also by the most communities seen as shame to the family of such person with disabilities (Mostert, 2016; Aley, 2016). People still expect no or low potential from people with disabilities and this can prevent children with learning disabilities to achieve sound education in school (Aley, 2016; DSPD, 2016; Inguanzo, 2017; Mostert, 2016). People in sub-Sahara Africa often do not see reason for helping these individuals but dread them or distance themselves from the disabled.

However, a researcher has found that students with disabilities who receive support services at their college are more likely to persist in their studies and graduate at the same rate as their peers without disabilities (Jorgensen, 2005). People with learning disability often experience verbal abuse and discrimination when attempting to gain employment, and they often fail to achieve socially valued goals, such as living independently, getting married and having a job (Beart, Hardy \& Buchan, 2005). Furthermore, a study has shown that peer rejection predicts learning difficulty and absence of social support from peer, making an individual have worse learning difficulty (Otte, Nahaga, Tchuda, Abna, \& Der Maas 2013). However, considering the above literatures calls for attention. This construct has not fully been investigated among schools for special needs in Nigeria. Based on existing gap in the literature, the need to fill this gap arises.

\section{Hypotheses}

i. There will be a significant relationship between demographic variables (gender, age, tribe, religion and unit), stigmatization, social support and learning difficult.

ii. Male participants will report significant higher learning difficulty than their female counterparts.

iii. Individuals with high perceived stigma will score significantly higher on learning difficulty compared to those with low perceived stigma.

iv. Respondents with high perceived social support will score significantly high on learning difficulty compared to those with low perceived social support.

v. Participants with intellectual impairment will exhibit more learning difficulty than those who have hearing impairment and those who are visually impaired.

\section{METHODS}

\section{Design}

This study employed a cross-sectional survey research design. The independent variables are perceived stigmatization and perceived social, support while the dependent variable is learning difficulty. 


\section{Sampling Technique}

The sampling technique employed was purposive sampling technique, which involves the selection of participants in such a way that it would follow the purpose of the study strictly by considering only the students with special needs (including males and females) who are the students of Kwara state school for special needs, Ilorin.

\section{Participants}

The participants were randomly selected purposively during questionnaires administration. A total of 120 respondents participated in this study which involved adolescent students of Home for Special Needs in Ilorin, Kwara State, Nigeria. Regarding participants age range, 8 to 13 (early adolescence) years were 19 (15.8\%), 14 to 19 years (middle adolescence) were 67 (55.8\%), 20 years and above (late adolescence) were 34 (28.3\%). Gender of the respondents: $68(56.7 \%)$ were males and $52(43.3 \%)$ were females. The Christian participants were $29(24.2 \%)$ and Muslims were $91(75.8 \%)$. As per their tribe and ethnicity, Yoruba respondents were 91 (75.8\%), Hausas were 17 (14.2\%), Igbos were 5 (4.2\%) and other tribes from minority groups in Nigeria were 7 (5.8\%). Considering their Units in school, those in hearing impairment unit were $78(65.0 \%)$, visually impairment unit were $33(27.5 \%)$ and intellectual challenge unit were $9(7.5 \%)$.

\section{Instrument}

This section consists of socio-demographic information of the participants, such as gender, age, religion, special school unit and tribe; the psychological instruments used were:

\section{"Perceived Stigma of Intellectual Disability Scale (PSIDS)}

PSIDS was developed by King, Dinos, Shaw, Watson, Stevens, Passetti, Weich \& Serfaty (2007) to assess perceived stigma by people with learning disability. It should be completed by people with disability, aged 8 and above, who have a reasonable level of comprehension. Individuals who have difficulty reading or have difficulty ticking the boxes, should be supported by their carer or a member of staff. In order to ensure that the person has understood all of the items, it is advisable that the person is offered assistance. It adopts a response format of "Yes" $=2$, "Undecided" $=1$, "No" $=0$. The instrument contains descriptions of experiences and feelings of stigma and includs negative and positive statements to reduce response set bias. Scoring: The scores of PSID scales involve asking the person to give an example of a situation in which the item under question occurred or re-phrasing the item. All of the ticks should then be added up to give a total score out of 20. The higher score starts from 10 and above, the higher the level of perceived stigma.

\section{Social Support Questionnaire (SSQ)}

This shortened version of SSQ was adapted and developed by Cohen, Mermelstein, Kamarck \& Hoberman (1985). It is a 12-item that measures perceptions of social support. This measure is a shortened version of the original 40 items Interpersonal Support Evaluation List (ISEL) (Cohen \& Hoberman, 1983). This questionnaire has three different subscales designed to measure three dimensions of perceived social support; the dimensions are: Appraisal support, Belonging support and Tangible support. The response is in multiple, thus: $1=$ definitely false, $2=$ probably false, $3=$ probably true and $4=$ definitely true. Scoring: Items 1, 2, 7, 8, 11 and 12 are reverse scored. Items 2, 4, 6 and 11 make up the Appraisal Support subscale; Items 1, 5, 7 and 9 make up the Belonging Support subscale; Items, 3, 8, 10 and 12 make up the Tangible Support subscale. Cronbach's alphas for the ISEL-12 total score was all above .70 in the full 
sample, English and Spanish, and all ancestries. The Appraisal, Belonging, and Tangible subscales (scores range 0-12) composed of four items each. Scores above 24 indicate high perceived social support of individual participant. The Cronbach's alpha reliability recorded for this current study on SSQ scales was .62.

\section{Colorado Learning Difficulties Questionnaire (CLDQ)}

CLDQ was developed by Willcutt, Boada, Riddle, Chhabildas, DeFries \& Pennington (2011) in University of Colorado to provide a brief screening measure for learning difficulties. It is a 20-item parent-report rating scale. The Cronbach's alpha recorded for this present study on CLDQ scales was .70. Scoring: Responses are rated on a 3-point Likert scale: (No $=0$, undecided $=1$, Yes $=2$ ). Items 1 to 6 relate to Reading, items 7 to 10 relate to Social cognition, items 11 to 13 relate to Social anxiety, items 14 to 17 relate to Spatial and items 18 to 20 relate to Math; 20 scores indicate average and above average shows learning difficulties.

\section{Procedure}

Before handing the questionnaire to each participant, a simple introductory discussion was conducted stating partial intent of the research so as to gain the participant's cooperation and sincerity. Also, after participants inform consent was obtained, the questionnaires were administered. The use of non-probability purposive sampling procedure was adopted. The participants were approached in their classroom after having sought the permission of the institution authority.

\section{Statistical Analysis}

Data were analyzed using (statistical packages for the social sciences) SPSS 20.0. Descriptive statistics such as Frequency, Mean, Standard Deviation and Variance were performed to describe the subject's information. Pearson Product Moment Correlation was used to analyze hypothesis one while t-test of independent sample was used to analyzed hypotheses two, three and four and One-way Analysis of Variance (ANOVA) was used to analyze hypothesis five. It was used to determine the influence of perceived stigmatization and social support on learning difficulty among individual students of Kwara State School for Special Needs.

\section{RESULTS}

Table 1. Socio-demographic Characteristics of Respondents $(n=120)$

\begin{tabular}{lll}
\hline \multicolumn{2}{c}{ Variables Frequency Percent } & \\
\hline Age Range & & \\
Early Adolescence (8-13yrs) & 19 & 55.8 \\
Late Adolescence (14-19yrs) & 67 & 28.3 \\
Young Adulthood (20 \& above yrs) & 34 & \\
Gender & & 56.7 \\
Male & 68 & 43.3 \\
Female & 52 & \\
Religion & & 42.2 \\
Christianity & 29 & 75.8 \\
Islam & 91 & 65.0 \\
School Unit Type & & 27.5 \\
Hearing Impairment & 78 & \\
Visually Impairment & 33 &
\end{tabular}


Intellectually Challenged

\section{Ethnicity}

Yoruba

Hausa

Igbo

Others
9

91

17

5

7
7.5

75.8

14.2

4.2

5.8

\section{Test of Inter-Variable Correlations}

Before the test of research hypothesis, the relationship existing among the variables such as: length of service, emotional exhaustion, job demand and work family conflict were examined and the results are presented below:

Table 2. Summary Showing Pair Wise Inter-Variable Correlations using Pearson Product Moment Correlations

\begin{tabular}{llllllllll}
\hline & & 1 & 2 & 3 & 4 & 5 & 6 & $\bar{x}$ & SD. \\
\hline 1 & Gender & - & & & & & & 1.43 & .498 \\
2 & Age & -.013 & - & & & & & 2.13 & .655 \\
3 & Unit & -.029 & -.013 & - & & & & 1.43 & .630 \\
4 & Perceived Stigma & -095 & .090 & -.143 & - & & & 10.74 & 4.55 \\
5 & Perceived Social Support & $-.205^{*}$ & .066 & .099 & .136 & - & & 29.10 & 6.22 \\
6 & Learning Difficulty & -.095 & .090 & -.143 & $.42^{* *}$ & .136 & - & 10.74 & 4.55 \\
\hline \multicolumn{7}{c}{$*$ Correlation is significant at the 0.01 level (1-tailed) } \\
& $*$ Correlation is significant at the 0.05 level (2-tailed).
\end{tabular}

\section{Dependent variable: Learning Difficulty}

Table 2 results shows that there is a significant positive relationship between perceived social support and learning difficulty $(\mathrm{r}=.42, \mathrm{p}<.01)$. However, there is no significant relationship between gender, type of disability, age, perceived stigmatization and learning difficulty, hence the need to test other hypothesis regarding the independent variables on dependent variable arises and is presented below:

Table 3. T-test Summary Table Showing Gender Differences on Learning Difficulty

\begin{tabular}{lllllll}
\hline Gender & $\mathbf{N}$ & $\bar{X}$ & Std & Df & T & P \\
\hline Male & 68 & 11.18 & 5.19 & & & \\
Female & 52 & 10.25 & 3.52 & 118 & 1.036 & $>.05$ \\
\hline
\end{tabular}

Table 3 presents the results related to the second hypothesis, which states the male participants will score high significantly on learning difficulty than female counterparts; there was no significant gender difference on learning difficulty $[\mathrm{t}(118)=.138 ; \mathrm{P}>.05]$ among the sampled participants. The result showed that male participants did not report higher learning difficulty than their female counterparts. The hypothesis is thus not confirmed.

Hypothesis three which stated that individual with high perceived stigma will score high significantly on learning difficulty compared to those with low perceived stigma is presented in table 4 below: 
Table 4. T-test Summary Table Showing the Differences in the levels of Perceived Stigmatization on Learning Difficulty

\begin{tabular}{lllllll}
\hline Perceived Stigma & $\mathbf{N}$ & $\bar{X}$ & Std & Df & T & P \\
\hline High & 80 & 13.38 & 2.53 & \multirow{2}{*}{118} & 15.70 & $<.01$ \\
Low & 40 & 5.48 & 2.73 & & & \\
\hline
\end{tabular}

Table 4 presents results of the third hypothesis, which states individual participants with high perceived stigmatization will score high significantly on learning difficulty than those with low perceived stigmatization; perceived stigmatization did influence learning difficulty. It was found that perceived stigmatization has significant influence on learning difficulty $[\mathrm{t}(118)=$ $15.70 ;<.05]$. The result shows that respondents with high perceived stigma $(\bar{X}=13.38$, $\mathrm{SD}=2.53$ ) scored higher significantly on learning difficulty compared to those with low perceived stigma from the sampled respondents ( $\bar{X}=5.48$, S.D $=2.97$ ). The hypothesis is thus accepted for this study.

Hypothesis four which stated that individuals with high perceived social support will score high significantly on learning difficulty compared to those with low perceived social support is presented in table 5 below:

Table 5. T-test Summary Table Showing the Differences in the levels of Perceived Social Support on Learning Difficulty among students with special needs

\begin{tabular}{lllllll}
\hline Perceived Social Support & $\mathbf{N}$ & $\bar{X}$ & Std & Df & T & P \\
\hline High & 116 & 10.79 & 4.52 & & & \\
Low & 4 & 9.25 & 2.85 & 118 & .666 & $>.05$ \\
\hline
\end{tabular}

Table 5 presents the results of the fourth hypothesis which states individual participants with high perceived social support will score high significantly on learning difficulty than those with low perceived social support; from the result, perceived social support did not influence learning difficulty. It was found that perceived social support had no significant influence on learning difficulty $[\mathrm{t}(118)=10.79 ;>.05]$. The result shows that respondents with high perceived social support ( $\bar{X}=10.79, \mathrm{SD}=4.52$ ) scored non-significantly on learning difficulty compared to those with low perceived stigma from the sampled respondents ( $\bar{X}=9.25$, S.D $=2.85)$. The hypothesis is thus rejected for this study.

Hypothesis five which stated that students with intellectual impairment will exhibit more learning difficulties than those who have hearing impairment and those who are visually impaired was tested using One-way Analysis of Variance (ANOVA) as presented in tables 6a and $6 \mathrm{~b}$ below: 
Table 6a. The significant influence of Types of Disability of Students with Learning Difficulty

\begin{tabular}{llllll}
\hline Source & SS & Df & MS & F & p \\
\hline Type of Impairment & 332.914 & 2 & 166.152 & 9.152 & $<.01$ \\
Error & 2128.078 & 117 & 18.189 & & \\
Total & 2460.992 & 119 & & & \\
\hline
\end{tabular}

Result from table 6a showed that the type of disability had significant influence on learning difficulty $(\mathrm{F}(2,117)=9.152, \mathrm{p}<.01)$. In order to ascertain the magnitude significant determinant of $\mathrm{F}$ Value, a multiple group comparison test was conducted. Consequently, Bonferroni post hoc analysis was used to compare the three groups. The results are shown in Table $6 \mathrm{~b}$ shown below.

Table 6b. The Summary of Bonferroni analysis of the influence of Types of Impairment of Students with Learning Difficulty

\begin{tabular}{lclllll}
\hline Groups & $\mathbf{N}$ & $\overline{\boldsymbol{X}}$ & SD & $\mathbf{1}$ & $\mathbf{2}$ & $\mathbf{3}$ \\
\hline 1. Hearing Impairment & 78 & 11.62 & 3.85 & 1 & & \\
2. Visually Impairment & 33 & 8.09 & 4.76 & $3.524^{*}$ & 1 & \\
3. Intellectual Impairment & 9 & 12.89 & 5.73 & -1.273 & $-4.798^{*}$ & 1 \\
\hline
\end{tabular}

The post-hoc result presented in table $6 \mathrm{~b}$ shows that with a total adjusted mean of 12.89 , intellectual impairment $(n=9)$ exhibited more learning difficulty when compared to the visually impaired $(\mathrm{n}=33)$, with a total adjusted mean of 8.09 , and those with hearing impairment $(\mathrm{n}=$ 78) with a total adjusted mean of 11.62. There is significant difference in the learning difficulty of the visually impaired and those with hearing impairment ( $M D=3.524 ; p<.05$ ), however, there was significant difference in the learning difficulty of the intellectually impaired and the visually impaired students ( $M D=-4.798 ; \mathrm{p}<.05$ ). However, there was no significant difference in the learning difficulty of intellectually impaired and the hearing-impaired individuals (MD $=1.127 ; \mathrm{p}>.05)$. The outcome of hypothesis five was in agreement with the hypothesis one, which stated that students with intellectual impairment will exhibit more learning difficulty than those who have hearing impairment and those who are visually impaired. Therefore, the stated hypothesis five is accepted.

\section{Discussion}

From hypothesis one, which states that there will be a significant relationship between demographic variables (gender, age, tribe, religion and special school unit), perceived stigma, social support and learning difficulty among the respondents, results from the study showed that there is no significant relationship between gender, type of disability, age, perceived stigma and learning difficulty, but there is a positive significant relationship between perceived social support and learning difficulty among participants. The result is in line with the studies carried out by Al-Yagon \& Mikulincer (2004), that discovered a positive relationship between social support and learning disabilities. This shows that an increase in social support is required for overcoming learning difficulty.

For hypothesis two, which states that individual males will score high significantly on learning difficulty compared to female counterparts, the results showed that male respondents did not report significant higher learning difficulty compared to female respondents. This result is in contrast to the study carried out in Kenya, which provides evidence regarding the "nature, 
extent, and significance of sex differences in reading difficulty" (Bunninn et al., 2017); they concluded that there is gender differences in learning disability and that boys have more difficulty than girls in visual-motor abilities, spelling, and mechanics in written language.

For hypothesis three, which states that individuals with high perceived stigma will score high significantly on learning difficulty compared to those with low perceived stigma among students with special needs, the results showed that respondents with high perceived stigma scored higher significantly on learning difficulty compared to those respondents with low perceived stigma. The result is supported by the research conducted by Jahoda and Markova (2004); the result indicated that people with a learning disability experience stigmatization in many areas of their lives and also these people with a learning disability are aware of this stigmatization which impacted negatively on their learning.

Hypothesis four states that individual with high perceived social support will score high significantly on learning difficulty compared to those with low perceived social support among students with special needs. The results showed that respondents with high perceived social support did not score low significantly on learning difficulty compared to those respondents with low perceived social support. Though it is believed that, without enough support from family and friends, one may find it difficult to succeed and may be vulnerable to depression, stress and anxiety which could result to learning difficulty (Otte et al., 2013; Gracia-Reid, 2007), this study found that social support does not influence learning difficulties. This contradiction could arise because the individuals with lower age like these participants may not really understand the major components of social supports except material needs, that may be germane and pertinent to them.

Hypothesis five states that students with intellectual impairment will exhibit more learning difficulty than those who have hearing impairment and those who are visually impaired. The results indicated that students with intellectual impairment did exhibit more learning difficulty than those who have hearing impairment and those who are visually impaired. The result corroborated the study carried out by Willcutt (2011); the study showed that children with moderate and high intellectual disability score high on learning disability compared to other children with behavioural disorder and hearing impairment.

\section{Conclusion}

Considering the findings of this study, the study shows that the prevalence of learning difficulty is higher among males than females. There is a significant positive relationship between perceived social support and learning difficulty. Gender did influence learning difficulty among the sampled respondents. Individuals with high perceived stigma did score high significantly on learning difficulty compared to those with low perceived stigma. Individuals with high perceived social support did not score low significantly on learning difficulty compared to those with high perceived social support among the respondents. Also, there was a significant difference in the types of impairment on learning difficulty among the sampled participants. Individuals with intellectual impairment did exhibited more learning difficulty than students with hearing and visual impairment.

\section{Recommendations}

Based on the results and findings, this study offers the following recommendations.

i. Government should come up with a policy that will discourage stigmatization against individuals with learning disability and psychological concepts will be integrated into the system of education of these individuals. 
ii. Parents, teachers and schools will be of great help providing support for disabled students, because disabled students who receive support from parents, teachers and schools are more likely to be successful academically.

iii. Programme should be organised to educate these individuals on how to cope or deal with stigma-induced identity threat posed to them from the society.

\section{REFERENCES}

Aley, R. (2016). An Assessment of the Social, Cultural and Institutional Factors that Contributeto the Sexual Abuse of Persons with Disabilities in East Africa. Advantage Africa. Retrieved from: https://www.advantageafrica.org

Al-Yagon, M., \& Mikulincer, M. (2004). Socio emotional and academic adjustment among children with learning disorders: The mediational role of attachment-based factors. Journal of Special Education, 38 (2), 111123.

American Psychiatric Association (2015). Diagnostic and Statistical Manual of Mental Disorders (5th ed., text revision). Washington DC: American Psychiatric Association.

Beart, S., Hardy, G., \& Buchan, L. (2005). How people with intellectual disabilities view their social identity: A review of the literature. Journal of Applied Research in Intellectual Disabilities, 18, 47-56

Berninger, V., \& May, M. (2011). Evidence-based diagnosis and treatment for specific learning disabilities involving impairments in written and/or oral language. Journal of Learning Disabilities, 44 (2), 167-18

Bond Disability and Development group (DDG). (2017). Stigma, disability and development. Bond. Retrieved from: https://www.bond.org.uk/sites

Bunning, K., Gona, J.K., Newton, C.R. \& Hartley, S. (2017). The perception of disability by Community groups: Stories of local understanding, beliefs and challenges in a rural part of Kenya. PLOS ONE. 12(8): retrieved from: https://doi.org/10.1371/journal

Cohen, S., \& Hoberman, H. (1983). Positive events and social supports as buffers of life change stress. Journal of Applied Social Psychology. 13; 99-125.

Cohen, S., Mermelstein, R., Kamarck T., \& Hoberman, H.M. (1985). Measuring the functional components of social support. In Sarason, I.G. \& Sarason, B.R. (Eds), Social support: theory, research, and applications. The Hague, Netherlands: Martinus Niijhoff

Division for Social Policy and Development (DSPD). (2016). Toolkit on Disability for Africa-Culture, Beliefs and Disability. Retrieved from UN. http://www.un.org

Garcia-Reid, P. (2007). Examining social capital as a mechanism for improving school engagement among low income Hispanic girls. Youth and Society, 39, 164-181

Hutchinson, N. (2007). Inclusion of exceptional learners in Canadian schools: A practical handbook for teachers. Toronto: Pearson.

Inguanzo, I. (2017). The situation of indigenous children with disabilities. Policy Department, Directorate-General for External Policies, European Union.

Jahoda, A. \& Markova, I. (2004). Coping with social stigma: people with intellectual disabilities moving from institutions and family home. Journal of Intellectual Disability Research, 48, 719-729

King, M., Dinos, S., Shaw, J., Watson, R., Stevens, S., Passetti, F., Weich, S., \& Serfaty, M. (2007). The stigma scale: development of a standardised measure of the stigma of mental illness. British Journal of Psychiatry 190:248-254.

Link, Bruce, \& Jo Phelan. (2001). Conceptualizing Stigma. Annual Review of Sociology, 24, 32-45

Mostert, M. (2016). Stigma as a barrier to the implementation of the Convention on the Rights of Persons with Disabilities in Africa. African Disability Rights Yearbook, 2-24.

Paget, A., Mallewa, M., Chinguo, D., Mahabere-Chrambo, C., \& Gladstone, M. (2016). “'It means you are grounded caregivers' perspectives on the rehabilitation of children with neuro-disability in Malawi. Disabil Rehabil. 223-234.

Scior, K. (2016). Intellectual Disabilities: Raising Awareness and Combating Stigma- a Global Review. University College London.

Shakespeare, T. (2014). Disability rights and wrongs revisited. 1st ed. London: Routledge.

Willcutt, E.G., Boada, R. Riddle, M. W., Chhabildas, N., DeFries, J.C \& Pennington, B.F. (2011). Colorado Learning Difficulties Questionnaire:Validation of a Parent-Report Screening Measure. Psychological Assessment, 23(3), 778-791. 